\title{
O mundo costeiro: temporalidades, territorialidades, saberes e alternatividades
}

\section{The Coastal World: The Temporal and Territorial Dimensions, Knowledge and Alternatives}

\author{
Lucia Helena de Oliveira CUNHA*
}

\begin{abstract}
RESUMO
O presente artigo busca configurar, em termos gerais, as dimensões temporais e territoriais do mundo costeiro centrando-se em seu sujeito principal - o pescador artesanal. Com base nos saberes e práticas patrimoniais dos pescadores costeiros em seus ritmos de tempo discute-se a relevância da construção do diálogo entre tradição e modernidade, em novas sínteses históricas, como alternativas - formuladas em gérmen - às ameaças exógenas que tais sujeitos sociais vêm sofrendo, no tempo e espaço, as quais tendem a desfigurar seu tradicional modo de vida. Propõe-se, também, o dialogismo entre as ciências da tradição e as ciências modernas, fundadas no paradigma da complexidade, para a construção de novos aportes com vistas à gestão compartilhada do ambiente costeiro e de seus recursos, ancorada na ética da sustentabilidade e colocando, assim, as sociedades costeiras em novo patamar histórico.
\end{abstract}

Palavras-chave: tempo natural; tempo do relógio; tradição e modernidade; diálogo entre tempos e saberes.

\begin{abstract}
This article aims to configure, in general terms, the temporal and territorial dimensions of the coastal world by focusing on its main subject - the artisanal fisherman. Based on the knowledge and patrimonial practices of the coastal fishermen within their time rhythms we discuss the role of the dialog between tradition and modernity, in new historical syntheses, as alternatives - germinally formulated - to the exogenous threats that these social subjects are suffering in a time and a space that tend to disfigure their traditional way of life. In addition, we propose the dialogism between the sciences of the tradition and the modern sciences based on the paradigm of complexity for the construction of new contributions as a means to shared management of the coastal environment and their resources, anchored to the sustainability ethics, and placing the coastal societies on a new historical level.
\end{abstract}

Key-words: natural time; clock time; tradition and modernity; dialog between time and knowledge.

\footnotetext{
* Antropóloga, Doutora em Meio Ambiente e Desenvolvimento, professora colaboradora e pesquisadora associada do Curso de Doutorado em Meio Ambiente e Desenvolvimento/UFPR, consultora do NUPAUB/USP e do Fórum da Agenda 21-Ibiraquera/SC/UFSC. E-mail: luelena.cunha@gmail.com.
} 


\section{Tempo natural e tempo do relógio: as distintas ordens temporais no ritmo de vida do pescador artesanal}

A reflexão que originou este artigo é fruto de diversos trabalhos realizados sobre o mundo costeiro no litoral sul do Brasil. Seu objetivo maior é o de configurar, em termos gerais, as dimensões temporais e territoriais desse mundo costeiro centrando-se em seu sujeito principal - o pescador artesanal.

No que diz respeito à dimensão temporal, Thompson (1998) fornece um interessante contraponto para entendermos a situação dos pescadores artesanais na contemporaneidade: o tempo natural - expressão do ritmo das chamadas sociedades tradicionais - e o tempo do relógio - expressão do ritmo dominante nas sociedades capitalistas industriais -, duas ordens temporais que estão presentes, de forma simultânea e contraditória, no ritmo de vida do pescador artesanal, quer no universo produtivo, quer em suas representações simbólicas.

Não obstante tenha se evidenciado, nas pesquisas realizadas, como tendência, o predomínio da segunda ordem temporal em relação à primeira - em face dos processos de urbanização e turismo e da inserção crescente da pesca nas redes de produção mercantil -, percebeu-se que, em muitos casos, ainda existe um tempo natural regulando a vida do pescador artesanal, numa situação em que o velho e o novo se combinam, imprimindo um ritmo singular à apropriação dos espaços naturais e sociais. Ou seja, observou-se, que, embora articulados nas teias sociais dominantes, os pescadores artesanais parecem não se encontrar nelas dissolvidos (CUNHA, 1987, 1996, 2001, 2002, 2003, 2006, 2007a, 2007b).

De qualquer maneira, pode-se dizer que o ritmo de trabalho integrante do passado dos pescadores era regulado pelo tempo natural em contraposição ao tempo do relógio que, de certa forma, se interpõe predominantemente na vida atual do pescador, como se poderá verificar. Anteriormente, sem uma medida abstrata e externa de tempo, o ritmo do pescador estava integrado à atividade pesqueira marcada pelos movimentos próprios da natureza.

Despossuídos de um tempo fixo e vazio, os pescadores artesanais eram, pois, portadores das mais ricas e variadas formas de temporalidade, contrapostas ao tempo quantitativo, cronometrado e mecânico dos tempos moder- nos - ainda que, recentemente, forças exógenas tendam a alterar essa situação. De qualquer forma, os ritmos sociais e naturais daquelas sociedades imbricam-se às suas atividades concretas e ao seu mundo imaginário.

Portanto, no passado histórico dos pescadores artesanais, conformava-se um ritmo peculiar no empreendimento de suas atividades, marcado pela predominância do tempo natural, dissonante do ritmo urbano-industrial, da disciplina da fábrica, da produtividade do capital.

É bem verdade que a metáfora que o tempo do relógio representa evidencia-se na atualidade, com a inserção dos pescadores nos processos modernos, mas, simultaneamente, o tempo natural ainda pulsa no dia a dia, nos intervalos dos afazeres que integram trabalho e vida, na alternância da pesca em seus ciclos internos. Assim, a ordem natural manifesta-se no próprio ritmo interno do ciclo da pesca os pescadores seguem a mobilidade das espécies em cada safra, baseados nos movimentos das marés, dos ventos e da influência dos astros no exercício de sua atividade.

Nesse sentido, é possível constatar, no interior das comunidades pesqueiras investigadas, a presença de um tempo cósmico regulando suas atividades ecoprodutivas e o horário do dia a dia. A lua, o sol e as estrelas atuavam no mundo da pesca e da agricultura, no passado, como marcadores de tempo, e ainda se pronunciam no presente do mundo costeiro, ainda que, muitas vezes, de modo difuso e fragmentário face às mudanças sociais que atingem as comunidades pesqueiras, desde a metade do século passado. Por exemplo, a lua é um dos astros que, de acordo com o tempo cósmico do pescador, atua em seu universo produtivo, ambiental e sociocultural, favorecendo boas ou más pescarias.

A lua mexe com a pesca, a lua mexe com tudo: tais expressões são muitas vezes evocadas pelos pescadores artesanais em diversas comunidades pesqueiras e integram particularmente o universo cósmico dos mais velhos. Pode-se constatar que a lua é o principal componente que atua no ciclo da maré, condicionando a elevação do nível do mar; a força da corrente, influindo na presença do peixe no espaço aquático e na modalidade de sua captura (CUNHA; ROUGELLE, 1989).

É interessante assinalar, conforme Maldonado (1993), que a noção de tempo e a de espaço é universal na cultura marítima, norteando o desempenho do trabalho, a utilização dos métodos de pesca e a organização social. Diz a autora que: 
[...] as horas de atividade, de captura e de navegação são determinadas pelos ciclos biológicos das diversas espécies, assim como por disposições outras que muitas vezes são de natureza social, como as dimensões e equipamentos que cada grupo dispõe determinarão o acesso ao mar e o tempo que passarão longe da terra firme (MALDONADO, 1993, p. 89).

O tempo do trabalho no mar é o que permite definir o tempo de trabalho em terra norteando o encadeamento das atividades e seus intervalos. De outro modo, a previsão desse tempo é em parte feita em terra, assim como o preparo das embarcações e a colocação das redes em seu interior, para a navegação e a realização das pescarias.

Convém salientar, aqui, que mesmo dependente das forças que regem o mundo marinho, não é a natureza em si que comanda a ordenação do trabalho do pescador, os intervalos e a sucessão das tarefas; portanto, seu ritmo de tempo é regido pela própria atividade, que se desenvolve na interseção entre cultura e natureza. Nesse sentido, é a modalidade da pesca que comanda o horário cotidiano do pescador artesanal perpassando tanto a vida laboral quanto a vida sociocultural como um todo, marcadas por temporalidades distintas.

\section{A territorialidade pesqueira ${ }^{1}$}

A trama de significações do universo pesqueiro se pronuncia na unidade espacial terra-mar-céu (ciclo lunar e processos atmosféricos), conformando um saber biocósmico que atua como regulador de acesso aos recursos naturais e à movimentação no espaço marítimo. Considerando que terra-mar-céu integram os saberes e a prática pesqueira de modo interconectado, evidencia-se no universo do pescador artesanal uma noção tridimensionada do espaço compondo sua territorialidade.

Além disso, os pontos cardeais funcionam como ordenadores, tanto na previsão do tempo, quanto na arte de navegação e na pesca propriamente dita, por exemplo, na forma de colocar as redes nos diversos pontos pesqueiros e lugares do mar, assim como nos caminhos da náutica pesqueira. Por esse motivo, o território da pesca artesanal não se conforma de maneira homogênea, sendo apropriado, de acordo com os movimentos dos peixes em cada safra, por grupos determinados de pescadores, no tempo e espaço.

A par da concepção tridimensionada do espaço, há que se considerar o mar como lócus privilegiado da reprodução social do pescador artesanal, onde a apropriação dos recursos pesqueiros se dá de forma indivisa. Embora essa apropriação não seja homogênea - realiza-se mediante o trabalho dos grupos pesqueiros - é possível configurar o mar como espaço de propriedade e acesso comum dos pescadores artesanais que dele extraem sua sobrevivência.

Aliás, convém salientar, esse espaço não se configura apenas como âmbito da sobrevivência material, mas também de sociabilidades distintas, marcadas por arranjos próprios no desenvolvimento das diversas modalidades de pesca e por representações simbólicas advindas da relação milenar ou secular do pescador com o mar.

Constatou-se que outrora essa unidade entre mar e terra se apresentava de maneira mais pronunciada, em vista de que os pescadores antigos capturavam os peixes nas proximidades da costa ou mais perto da terra e diversificavam suas atividades nesse ambiente - aí se localizava sua moradia, os ranchos de pesca, os lugares onde teciam suas redes, consertavam suas embarcações e faziam suas plantações.

Se no mar ocorre a busca do pescado, na terra ocorre a complementação da atividade pesqueira: seja onde fica sua morada, seja onde entralham as redes, consertam e fazem a manutenção de seus equipamentos (em geral nos quintais de casa), seja, ainda, onde guardam e conservam seus apetrechos de pesca. A maior parte das embarcações, em geral, permanece no porto, assim como há ainda alguns ranchos de pesca à beira da praia em algumas comunidades pesqueiras, diferentemente do passado, quando se espraiavam nesse espaço.

\footnotetext{
${ }^{1}$ Para efeito deste estudo, define-se territorialidade como formas específicas de apropriação de um determinado espaço ou "como o esforço coletivo de um grupo social para ocupar, usar, controlar e se identificar com uma parcela específica de seu ambiente biofisico, convertendo-o em seu território" (LITTLE, 2002, p.2). Na perspectiva de focar a relação que um determinado grupo social possui com seu território, Paul Little se vale do conceito de cosmografia, conceito esse muito valioso para os propósitos da presente reflexão, centrada nas dinâmicas pesqueiras de caráter artesanal. Assim, cosmografia é, segundo esse autor, entendida "como os saberes ambientais, ideologias e identidades - coletivamente criados e historicamente situados - que um grupo social utiliza para estabelecer e manter seu território. A cosmografia de um grupo inclui seu regime de propriedade, os vínculos afetivos que mantém com seu território específico, a história da sua ocupação guardada na memória coletiva, o uso social que dá ao território e as formas de defesa dele" (LITTLE, 2002, p. 4).
} 
Ademais, numa relação de complementaridade, terra e mar contêm significados distintos em relação aos movimentos cruciais que permeiam o ciclo de trabalho, os quais podem ser traduzidos da seguinte maneira: na terra é o tempo de espera que prevalece; no mar é o tempo de procura do pescado. Isso se liga ao fato de a captura de peixes e crustáceos consistir no momento principal do ato produtivo - o tempo do trabalho propriamente dito.

Por outro lado, se o espaço próximo da beira da praia permitia no passado (e no presente) - em particular com o arrasto da tainha ainda praticado em várias comunidades costeiras - uma proximidade com a terra, a pesca no mar alto provoca quase uma ruptura, certo desgarramento do espaço terrestre. Se, como visto, há uma complementaridade entre mar e terra na vida do pescador artesanal, o distanciamento cada vez maior da terra (ou da costa) se configura também como uma relação de oposição entre esses espaços.

Tanto no passado quanto na atualidade, os pescadores revelaram conhecer também o ciclo migratório dos peixes e sua mobilidade espacial - pois eles se deslocam em direções distintas, de acordo com as correntes marítimas. Atuando em vários planos espaciais marítimos - tanto na superfície como no fundo do mar, nas proximidades da beirada e em espaços mais longínquos - conhecendo os caminhos do mar e as rotas de navegação, os pescadores seguem os movimentos da natureza e das espécies, explorando seu território produtivo, social e cultural de modo peculiar.

Além disso, é em terra que se engendra a divisão do trabalho por gênero e idade. Nesse espaço o pescador realiza trabalhos acessórios, nele passando também seus momentos de descanso, porquanto, mesmo sem permanecer inativo, ele desfruta aí de seu tempo livre. Entre uma atividade e outra, não há marcações de tempo fixo.

Assim, segundo observa Maldonado (1993, p. 261), os termos terra e mar que compõem a díade básica à ordenação do espaço nas sociedades pesqueiras são mais do que a expressão de realidades espaciais empiricamente reconheciveis ou de atributos físicos [...]; são termos carregados de concretude e significações simbólicas.

Nas localidades investigadas, o espaço do mar apresenta-se como espaço essencialmente masculino, embora existam mulheres em algumas comunidades do litoral sul-sudeste que realizam a atividade pesqueira em busca de sobrevivência. Se, no passado das comunidades em foco, as mulheres participavam em terra da confecção das redes e escalagem do peixe, e também nos trabalhos do roçado, estando presentes na fabricação da farinhada, na atualidade permanecem circunscritas ao mundo doméstico - apenas em algumas comunidades por nós investigadas as mulheres participam da venda do pescado no mercado local. Porém, pode-se dizer que tanto mulheres quanto crianças, junto dos homens do mar, participam da pesca ou do arrasto da tainha na época em que é possível capturá-la.

De qualquer forma, não se pode desconsiderar sua participação direta e indireta no universo pesqueiro: quer acompanhando continuamente seus maridos nas idas e vindas do mar; quer nas conversas diárias que entabulam sobre a pescaria; quer por seu conhecimento da variedade dos tipos de pescado, expresso, principalmente, em sua arte de cozimento.

Convém observar que a exploração dos espaços mar e terra - dependendo dos atores sociais aí inscritos, adquire significações próprias, diferenciadas e até opostas. Por exemplo, o mar, para o veranista, é carregado de imediatismo e dotado de inscrição temporária - objeto de contemplação e consumo; para as empresas pesqueiras e atravessadores, o mar é apenas mercadoria - espaço de lucratividade; para o pescador artesanal é lugar de trabalho e vida. Nesse sentido, além de constituir espaço de sobrevivência, representa também um local de cultura e de formas de sociabilidade próprias.

É interessante observar, aqui, como os espaços terra e mar adquirem também significados distintos no universo do pescador artesanal, tendo-se em mente as próprias comunidades pesqueiras investigadas em sua percepção da natureza. Assim assinala Silva:

Os pescadores compreendem a natureza em dois gran-
des mundos: o do mar e o do seco (terra), sendo que o
primeiro é tido como um espaço muito especial, digno
de muita reflexão e admiração. Este mundo, construído
em torno do mar, engloba também céu, nuvens, chuvas
e ventos que possam vir a compor o cenário do homem
embarcado. O mundo do seco constitui-se de uma natu-
reza dócil, previsível, passível de ser controlada no que
diz respeito a certas leis e ciclos e, na medida em que
a sociedade é [geralmente] vista como uma dimensão
deste mundo, as regras sociais também reforçam esta
expectativa de previsibilidade [...] (SILVA, 2000a, p. 28)

Por sua vez, para essa autora, o espaço marítimo, visto como entidade viva, é regulado por um modo orgânico que 
se diferencia da conformação do espaço terrestre; naquele, superpõem-se imprevisibilidade e regras, seja em função do inesperado, seja pelo fato de o mar ter suas constâncias, suas fases conhecidas pelo pescador. Nesses termos é que se evidencia que o mar é simultaneamente marcado por regularidades e irregularidades (ordens e desordens ${ }^{2}$ ), processos presentes no próprio horizonte do pescador.

Verificou-se que se, por um lado, a interação do pescador com o mar é marcada por desordens criadoras, por outro lado, desordens destruidoras ${ }^{3}$ de caráter socioambiental se pronunciam simultaneamente nesse universo, o que requer a construção de projetos amplos, de caráter sustentável, para suplantá-las.

As desordens destruidoras presentes na territorialidade própria do pescador artesanal, tanto na terra como no mar, podem ser assim condensadas: a desarticulação da agricultura de subsistência no passado histórico das comunidades investigadas - por volta da metade do século 20 - que, em combinação com a atividade pesqueira, produzia diversidade ambiental, econômica e social - levando a pesca a se constituir atualmente numa atividade exclusiva e especializada; a escassez dos recursos com a diminuição dos estoques pesqueiros, gerada por sobrepesca ou métodos inadequados; a dependência ao intermediário, que conduz a exploração dos ganhos de produção do pescador, com preços variados e abaixo da sua produtividade, o que não permite sua construção histórica como produtor autônomo; a pressão dos recursos pela pesca industrial ou empresarial, que produz impactos ambientais de grande monta no território da pesca artesanal, ameaçando fortemente a territorialidade própria do pescador artesanal; a expansão do turismo e da urbanização, levando à redefinição ou à descaracterização das formas de sociabilidade e estilo de vida tradicional, em particular com a transformação de suas áreas ancestrais em balneários: expulsos de suas casas próximas da praia, onde viviam concentrados em pequenos agrupamentos, muitos pescadores, hoje, vivem espalhados em situações de contraste em meio a construções de hotelaria, bares, restaurantes e casas de veranistas (ou de segunda residência), que ocupam o espaço tradicional do pescador de forma desordenada e, muitas vezes, de modo efêmero - nas temporadas.
Como consequência, ocorre a separação entre trabalho e moradia, assim como a tendência ao esmaecimento dos laços de vizinhança e das relações face a face que predominavam com intensidade no passado, em particular na vida em terra. Correlativamente, desorganizam-se formas de sociabilidade das comunidades pesqueiras investigadas.

A ruptura dessa unidade espacial e territorial, bem como dos ritmos temporais próprios do universo costeiro, engendrada por forças exógenas, pode levar à desterritorialização ou à desarticulação das formas tradicionais de organização dos pescadores artesanais, embora se deva levar em conta movimentos socioambientais que produzem sujeitos sociais e políticos propugnadores de alternatividades em favor da permanência no tempo e espaço da pesca costeira, ainda que atualizada no fluxo da história, em novo encontro entre tradição e modernidade.

\section{Alternatividades no mundo costeiro: diálogos entre tempos e saberes}

Considerando que os pescadores estão imersos em processos modernizantes - muitos dos quais produtores de desordem destruidora -, um projeto amplo de sustentabilidade, tanto no plano social quanto no ambiental, exige paradigmas criativos e inovadores, que possam colocar em novos termos a relação entre tradição e modernidade, como processos que possam produzir novos arranjos socioculturais e ambientais.

Em conformidade ao que foi apontado, é preciso salientar que, embora conectadas, tradição e modernidade não podem ser vistas como imagens especulares invertidas uma da outra. O que se quer realçar é que não há de um lado a estática e de outro a dinâmica, ambas correspondendo à ordem e à desordem, respectivamente, como se o conflito fosse condutor das mudanças e a estabilidade, reguladora das tradições. Em verdade, como visto no âmbito da dinâmica pesqueira artesanal, a tradição se repõe na modernidade em suas diversas formas, como presença e como ausência, como ser e não-ser, já que elementos do passado permanecem e se atualizam no presente. De outro modo, ainda que muitas vezes de maneira perversa, a modernidade se impõe nas

\footnotetext{
${ }^{2}$ Ver a noção de ordem e desordem com que trabalhei na minta tese de Doutorado, Ordens e Desordens socioambientais: saberes tradicionais em dinâmicas pesqueiras da costa paranaense, com base particularmente em George Balandier, na obra A desordem - elogio do movimento (BALANDIER, 1997), e em Edgar Morin, Ciência com consciência, s/d.

${ }^{3}$ A diferenciação entre desordem criadora e desordem destruidora está presente em Balandier (1997).
} 
comunidades pesquisadas com múltiplas facetas, o que não permite pensar sua dinâmica homogênea e univocamente - fechada como um monolito.

O que importa marcar, aqui, é que tanto o tradicionalismo quanto o modernismo presentes nas comunidades pesqueiras devem ser vistos, na história, como estando em permanente movimento - o que pode ensejar um leque aberto de possibilidades de conjunção entre distintas temporalidades. $\mathrm{O}$ que se postula é um novo encontro histórico entre tradição e modernidade, que permita articular simultaneamente passado, presente e futuro numa ressignificação temporal; encontro este que permita aos pescadores artesanais (re) inscrever-se em sua história de modo protagônico.

Em outros termos, reinventando a tradição e livrando-se dos fetiches da modernidade - considerando que as possibilidades da modernidade não estão exauridas em sua positivação -, postula-se também a absorção de experiências modernas, ainda que redefinidas, naquilo em que possam potencializar a própria tradição: em ato de entrega (ou de troca) de conhecimentos e tecnologias ambientalmente apropriadas, tais intercâmbios podem atuar na abertura para o novo, para a construção de novas sínteses históricas. Coloca-se, assim, a necessidade de construir o novo fundado, porém, em elementos da tradição, que em combinação com processos modernos alternativos, transforma o passado em elemento ativo; de outro lado, a modernidade não deve ser encarada meramente em sua face destruidora - em recombinação com a tradição, ela também se pode transformar em tempo de criação (elemento positivo).

Nesse sentido, é significativa a observação de Morin, em seu livro Terra pátria, ensejando uma profunda reflexão. Assim afirma ele:

Certamente não devemos idealizar as culturas (...) Temos igualmente de manter a necessidade de uma cultura planetária. Todavia, não poderemos extrair de cada uma e generalizar o que ela trouxe de mais rico? Como integrar então os valores e tesouros culturais das culturas que se desintegram? Não será demasiado tarde? (MORIN; KERN, s/d, p. 67). [sem grifos no original]

Conquanto esse autor acentue a crise da modernidade (e da própria tradição), há em seu pensamento a necessidade de uma nova política de hominização e uma ética do futuro repleta de possibilidades, na qual os tesouros culturais das sociedades da tradição possam ter lugar.
Assim, uma nova relação entre o pescador e a natureza - fundada em nova ética - implica um olhar sábio e simultâneo para a frente e para trás; ou, numa linha de rotação do tempo, um olhar que envolva o atrás sem ir para trás, o que permite pensar no enlaçamento entre os tempos de ricas e distintas maneiras e na reconstrução de sua territorialidade.

Isso requer pensar em novos paradigmas que permitam, a um só tempo, resgatar e restaurar a tradição pesqueira (ou os saberes da tradição) sob novos termos num circuito interativo entre temporalidades distintas, que possibilite a conjunção entre tradição e modernidade, entre o saber patrimonial e o saber científico e entre saberes transgeracionais, numa relação de coetaneidade.

O que se postula é uma nova conexão entre cultura e natureza nas formas tradicionais em que se realize uma recombinação com a modernidade, sem prescindir do saber biocósmico presente, secular ou milenarmente, entre as populações costeiras.

Assim, esse conhecimento, ungido de diálogos e duelos com os próprios movimentos da natureza, deve ser atualizado, restaurado e revigorado para a sua própria permanência no tempo; particularmente em face da premência de novos paradigmas de uso sustentável dos recursos naturais que, sem abstrair a importância do conhecimento tradicional das comunidades pesqueiras nas localidades pesquisadas, devem colocar em outro patamar as suas condições de vida.

Tal proposição alcança relevância levando-se em conta, principalmente, que essas comunidades pesqueiras vêm enfrentando, desde meados do século passado e início deste milênio, perda progressiva de espaço vital e de acesso ao mar, o que as tem conduzido a viver, muitas vezes, num mundo de desordens ambientais e socioculturais destruidoras. A escassez dos recursos pesqueiros, manifesta de forma cada vez mais intensa na atualidade, constitui um dos pontos nodais que comprometem a sobrevivência física e social do pescador artesanal; a reorganização das comunidades pesqueiras em novas bases poderá evitar que tais comunidades conformem uma sociedade de risco (BECK, 2001), marcada por desordens destruidoras em todos os níveis da vida, em vista de que a consciência dos riscos socioambientais já integra nitidamente o universo do pescador, em inúmeros depoimentos de diversas comunidades pesqueiras.

A construção de um diálogo fecundo entre saberes de várias ordens, para a construção de sustentabilidade na produção pesqueira de modalidade artesanal, deve colocar em cena expressões de saber e cosmovisões tecidas ao lon- 
go do tempo para a produção e recriação da vida em suas múltiplas dimensões.

Configurando-os com parte integrante do saber ambiental, Leff (2001a) - um dos propositores do diálogo entre saberes para a produção de um novo conhecimento - afirma a importância de saberes que, com matrizes próprias, condensam os sentidos inscritos em vários tempos que se articulam, tanto físicos quanto biológicos, como os tempos cósmicos, os quais regem as concepções e apropriações sobre o mundo das diferentes culturas que compõem a história.

Nessa linha de pensamento, esse autor fornece contribuições bastante relevantes sobre a necessidade de fecundar esse diálogo entre saberes tradicionais e modernos, gerando um novo encontro entre esses conhecimentos dotados de lógicas próprias. Esta perspectiva rompe com o colonialismo de um saber que, historicamente, se processa quando agentes externos (como instituições governamentais e até as não governamentais) atuam de forma autoritária e unilateral em relação às sociedades tradicionais.

Sob esse prisma, há que se buscar formas de interação entre outros aspectos do conhecimento, considerando que a instauração do diálogo entre saberes pressupõe a articulação de discursos diferentes e contraditórios em seu capital argumentativo e não a construção de verdades absolutas e unilaterais, centradas numa relação de poder. Ressalta-se que é no interior dessa relação que muitas vezes se explicita o poder dos agentes de fora no universo dos pescadores artesanais, dos meios de comunicação de massa (dos processos turísticos e de urbanização), do global sobre o local e do conhecimento científico sobre o conhecimento tradicional.

Reconhecendo, pois, o estatuto e o valor de saberes milenares ou seculares das sociedades da tradição, Leff(2001a, p. 188-189) propõe, em termos epistemológicos e políticos, um diálogo entre os saberes de diversas ordens para a construção de um novo modelo de conhecimento que rompe com os padrões da ciência formal. Assim observa ele:

[...] isso implica a necessidade de desconstruir a racionalidade que fundou e construiu o mundo, no limite da razão modernizadora que a conduziu a uma crise ambiental, para gerar um novo saber no qual se reinscreve o ser no pensar e se reconfiguram as identidades, mediante um diálogo de saberes (encontro, enfrentamento, intercruzamento, hibridação, complementação e antagonismo) na dimensão aberta pela complexidade ambiental para o reconhecimento e re-apropriação do mundo (LEFF, 2001a, p. 188-189).
Entretanto, convém observar que é possível considerar que o conhecimento tradicional do pescador artesanal - diferentemente da ciência formal cindida em sua lógica interna por saberes especializados - conforma-se numa perspectiva holística, em que a percepção e compreensão dos fenômenos naturais que compõem seu universo se exprimem de modo integrado. Por isso afirma-se a necessidade de que um diálogo entre saberes, que conduza a novos modelos de conhecimento, seja instaurado numa comunicação profícua com paradigmas emergentes, que propugnam uma visão totalizante das distintas expressões do conhecimento geradas pela história humana, numa lógica sistêmica aberta, a um só tempo, dialógica e dialética.

Mesmo que esquecidos ou escondidos às margens da história, os pescadores artesanais, desde finais do século passado e início deste milênio, vêm adquirindo certa visibilidade no contexto de seus próprios movimentos sociais e de embriões de experiências de caráter socioambiental, em várias partes do litoral brasileiro. Apesar disso, os pescadores do litoral sul brasileiro - particularmente nos casos examinados somente poderão superar a crise que envolve o mundo pesqueiro artesanal se, a exemplo do MONAPE (Movimento Nacional dos Pescadores), construírem uma identidade de projeto (CASTELLS, 1999) que preconize alternativas sustentáveis para assegurar a sua permanência na história como sujeitos autônomos. A unidade de uso sustentável presente no Sistema Nacional de Conservação (SNUC) - Reserva Extrativista - tem sido uma das alternativas propugnadas pelo MONAPE (a exemplo do que ocorre com os povos da floresta, que deram origem à proposta deste tipo de unidade de conservação, como a primeira unidade de uso direto a integrar a política ambiental brasileira) para salvaguardar a biossociodiversidade da vida marinha em suas múltiplas dimensões e assegurar um futuro sustentável para as comunidades pesqueiras de modalidade artesanal.

Assim, para alcançar maior visibilidade e legitimidade dos atores sociais em questão - os pescadores artesanais -, e de novas formas de cogestão socioambiental (ou gestão patrimonial compartilhada), torna-se necessária sua organização em movimentos socioambientais propositivos de caráter contra-hegemônico para a construção de alternatividades, de um novo modelo de desenvolvimento (ou de novas formas societárias que conjuguem cultura e natureza em termos coevolutivos) em oposição ao modelo hegemônico.

Isso requer o reconhecimento e a valorização de formas de conhecimento, em diferentes expressões, que legitimem 
os saberes patrimoniais dos pescadores artesanais acerca dos movimentos da natureza marítima (ondas, marés, correntes, ventos, tempestades e ressacas), do ciclo interno da pesca, de seu calendário, da migração e dos lugares onde se encontram peixes, da influência lunar nas pescarias, das rotas de navegação, pois decorrem daí os mecanismos de adaptação às dinâmicas marítimas, mesmo que articulados com processos modernizantes. Além disso, há que se levar em conta a contribuição milenar ou secular dos pescadores artesanais para a construção de uma sociedade sustentável numa perspectiva intercultural, a partir de sua relação histórica com a natureza marinha.

Como se viu, isso não significa que os pescadores artesanais não possam incorporar outras modalidades de conhecimento numa relação dialógica que permita a gestão socioambiental em termos amplos, sem que esta se restrinja - como comumente se faz - aos planos de manejo ditos racionais, de caráter tecnicista, gerados no âmbito da tec-

\section{Referências}

BALANDIER, G. A desordem - elogio do movimento. Rio de Janeiro: Bertrand Brasil, 1997.

BECK, U. Épistémologie politique de la société du risque. In: . La société du risque: sur la voie d'une autre modernité. Paris: Alto Aubier, 2001.

CASTELLS, M. O poder da identidade. v.2. São Paulo: Paz e Terra, 1999. (Coleção A Era da Informação: Economia, Sociedade e Cultura).

CORDELL, J. The Lunar-Tide Fishing Cycle in Northeastern Brazil. Ethnology, v.13, n.4, p. 379-392, 1974.

CUNHA, L. H. Entre o mar e a terra: tempo e espaço em Barra da Lagoa/SC. 1987. 244p. Dissertação (Mestrado) - Programa de Estudos Pós-Graduados em Ciências Sociais. Pontifícia Universidade Católica de São Paulo. São Paulo, 1987.

Tradição e modernidade: conexões e (des) conexões. São Paulo: PUC, 1996. (Texto elaborado para o Programa de Estudos Pós-Graduados em Ciências Sociais/PUC-SP inédito).

Olhares sobre a tradição. Desenvolvimento e Meio Ambiente: teoria e metodologia em meio ambiente e desenvolvimento. Curitiba, n. 4, p. 29-35, 2001. nocracia e da ciência formal, de modo exterior, ignorando saberes ambientais seculares.

Um fórum permanente de troca ou permuta de ideias e experiências entre o saber patrimonial do pescador e o saber científico baseado nos paradigmas da complexidade que incorporam a ciência da tradição, numa circulação dialógica, poderá gerar propostas ou programas concretos que levem à melhoria das condições de vida das populações pesqueiras, conduzindo-as a um modo sustentável, econômico, social, cultural e ambiental de reapropriação social da natureza.

$\mathrm{O}$ elo entre distintos mundos e temporalidades $-\mathrm{em}$ territórios próprios - talvez permita a construção de uma casa comum, em que haja lugar para os múltiplos e diversos modos de vida - inclusive os dos povos do mar-, em uma polifonia de vozes fundada na ética da sustentabilidade, numa nova conexão entre natureza e cultura em encontro fecundo (confronto) com a história.

. Movimentos, tempo e natureza: o singular e o universal. Revista Margem. São Paulo, n. 15, p. 121-133, 2002.

Saberes patrimoniais pesqueiros. Desenvolvimento e Meio Ambiente: diálogo entre saberes e percepção ambiental. Curitiba, n.7, p. 69-76, 2003.

Diálogos entre saberes na pedagogia ambiental: transpondo dicotomias entre teoria e ação. In: CONGRESSO IBEROAMERICANO DE EDUCAÇÃO AMBIENTAL, 5, 2006. Joinville. Anais.

Ordens e Desordens Socioambientais: saberes tradicionais em dinâmicas pesqueiras da costa paranaense. 2007. 204p. Tese (Doutorado) - Universidade Federal do Paraná. Curitiba, 2007a.

. A identidade caiçara: entre o local e o global. São Paulo: NUPAUB-USP, 2007b.

CUNHA, L. H.; ROUGEULLE, M. Comunidades litorâneas $e$ unidades de proteção ambiental: convivência e conflitos; o caso de Guaraqueçaba. São Paulo: NUPAUB-USP, 1989.

DIEGUES, A. C. Diversidade biológica e culturas tradicionais: o caso das comunidades caiçaras. São Paulo: NUPAUB-USP, 1988. 
Tradição e mudança nas comunidades de pescadores do Brasil: por uma socioantropologia do mar. In: ENCONTRO DE CIÊNCIAS SOCIAIS E O MAR NO BRASIL, 3, 1989. Pesca artesanal: tradição e modernidade. São Paulo. Anais.

. Etnoconservação da natureza: enfoques alternativos. In: DIEGUES, A. C. (Org.). Etnoconservação: novos rumos para a proteção da natureza nos trópicos. São Paulo: Hucitec, 2000.

. História e memória caiçara. In: DIEGUES, A. C. (Org.). Enciclopédia caiçara. v.4. São Paulo: Hucitec; NUPAUB-CEC/USP, 2005.

O patrimônio cultural caiçara. In: DIEGUES, A. C. (Org.). Enciclopédia caiçara. v. 5. São Paulo: Hucitec; NUPAUB-CEC/USP, 2006.

DIEGUES, A. C.; ARRUDA, R. V. Saberes tradicionais e biodiversidade no Brasil. Brasília: Ministério do Meio Ambiente; NUPAUB-USP, 2001. (Série Biodiversidade, v.4).

LITTLE, P. E. Territórios sociais e povos tradicionais no Brasil: por uma antropologia da territorialidade. Brasília: Universidade de Brasília, 2002.

LEFF, E. Epistemologia ambiental. São Paulo: Cortez, 2001a. Saber ambiental: sustentabilidade, racionalidade, complexidade, poder. Petrópolis: Vozes, 2001b.

MALDONADO, S. Pescadores do mar. São Paulo: Ática, 1986.
Mestres e mares: espaço e indivisão na pesca marítima. São Paulo: AnnaBlume, 1993.

MORIN, E. Ciência com Consciência. Lisboa: Europa-América, [s.d.].

MORIN, E.; KERN, A. B. Terra pátria. Lisboa: Instituto Piaget, [s.d.]. (Coleção Epistemologia e Sociedade)

SILVA, G. Água, vida e pensamento: um estudo de cosmovisão entre trabalhadores da pesca. In: DIEGUES, A. C. (Org.). A imagem das águas. São Paulo: Hucitec, 2000a.

Tudo que tem na terra tem no mar. In: DIEGUES, A. C. (Org.). A imagem das águas. São Paulo: Hucitec, 2000b.

O tempo natural. In: SILVA, L. G. A faina, a festa e o rito: uma etnografia histórica sobre as gentes do mar (sécs. XVII ao XIX). Campinas: Papirus, 2001.

THOMPSON, E. P. Tempo, disciplina de trabalho e capitalismo industrial. In: THOMPSON, E. P. Costumes em comum. Trad. Rosaura Eichemberg. São Paulo: Companhia das Letras, 1998.

VIEIRA, P. V. Gestão patrimonial de recursos naturais: construindo o ecodesenvolvimento em regiões litorâneas. In: CAVALCANTI, C. (Org.). Desenvolvimento e natureza: estudos para uma sociedade sustentável. São Paulo: Cortez, 1995.

Recebido em setembro de 2009.

Aceito em dezembro de 2009.

Publicado em dezembro de 2009. 